\title{
Exploring practices in collaborative innovation: Unpacking dynamics, relations, and enactment in in-between spaces
}

Anna Yström and Marine Agogue

The self-archived postprint version of this journal article is available at Linköping University Institutional Repository (DiVA):

http://urn.kb.se/resolve?urn=urn:nbn:se:liu:diva-163704

N.B.: When citing this work, cite the original publication.

Yström, A., Agogue, M., (2020), Exploring practices in collaborative innovation: Unpacking dynamics, relations, and enactment in in-between spaces, Creativity and Innovation Management.

https://doi.org/10.1111/caim.1236o

Original publication available at:

https://doi.org/10.1111/caim.12360

Copyright: Wiley (24 months)

http://eu.wiley.com/WileyCDA/ 
Citation: Yström, A., \& Agogué, M. (2020). Exploring practices in collaborative innovation: Unpacking dynamics, relations, and enactment in in-between spaces. Creativity and Innovation Management, 29(1), 141-145.

\title{
Exploring Practices in Collaborative Innovation: Unpacking Dynamics, Relations, and Enactment in In-Between Spaces
}

\author{
From the Editors
}

\section{Abstract}

In the field of innovation management, the study of collaborative innovation has primarily focused on the type of networks to support innovation, the modularity of the product's architecture required to engage actors in collaboration, the strategies for patenting and knowledge appropriation, and the public policies likely to stimulate collaborative innovation. But given that many efforts to collaborate collapse and fail to generate the desired innovative value, previous research needs to be complemented with perspectives on what individuals and collectives actually do when creating collaborative innovation as they engage in "in-between spaces", a space between actors created by and simultaneously creating social interaction, to understand the practices that both form and constitute the collaboration. Through such studies, new knowledge can be created building on detailed insights about what ensues as different actors engage in interaction to innovate together and contribute to identifying levers to build collaborative spaces that indeed foster innovation. With this special section, we wish to encourage innovation management scholars to rethink their approach to collaborative innovation research by complementing macro-level insights with an exploration of the microfoundations of collaborative innovation to gain a more nuanced understanding of collaborative dynamics, relations and enactment.

\section{Doing innovation together in "in-between" spaces}

With the aim to advance our understanding of collaborative innovation, this special section is composed of three papers that are the result of the work of researchers from different continents using contrasting approaches (a longitudinal case study, ethnography and action research) and set in varied fields (in the academic world, the semiconductor industry and the creative industries). The interest in this special section exceeded our expectations by far, and we relied on the essential contributions of more than thirty reviewers in the process as well as the dedicated support of the editors of the Creativity and Innovation Management Journal, Jennie Björk and Katharina Hölzle. The result is a rich collection of pieces representing an initiative to engage in in-depth reflection on evolving practices in collaborative innovation.

Collaborative innovation is a broad term, and we propose to define it as innovation activities or innovation processes involving multiple actors, organizations or individuals transcending boundaries (within or across organizations) with the purpose of creating and developing new products, services, policies, processes or business solutions. This special section is motivated by both practical and theoretical concerns related to a shift in how organizations engage in innovation activities. Organizations increasingly engage in collaborative innovation and do so 
in various ways e.g. with partners, suppliers, customers and users, by bridging organizational boundaries to tap into knowledge from different sources and by co-creating solutions (Baldwin \& von Hippel, 2011; Bogers et al., 2017; Huizingh, 2011). It appears that for many organizations, collaboration has become necessary in order to tackle complex problems (M Agogué, Yström, \& Le Masson, 2013; Dougherty, 2017) by bringing in and combining different skills, expertise and experiences.

Ollila and Yström (in press) argue that such collaboration to achieve innovation takes place in an "in-between space", a space (physical, cognitive as well as virtual) in-between actants, with its own character and value. As such it resembles a liminal space (Bhabha, 1994) which is both familiar and different from ordinary everyday organizational work. The space is characterized as 1) multiplex (diverse) 2) in-becoming (emergent) 3) recursive (mutual shaping of actors and spaces) and 4) translative (bridging cultures and logics) (Susanne Ollila \& Yström, in press). As such the "in-between space" brings together ideas of "relational spaces" (Kellogg, 2009) outlining the influence of cross-hierarchical relationships in times of change, the "trading zone" (Kellogg, Orlikowski, \& Yates, 2006), illustrating practices of cross-boundary coordination in post-bureaucratic work, as well as "interstitial spaces" (Furnari, 2014), where individuals socialized into different institutions are able to temporarily break free from existing institutions and experiment collectively with new activities and ideas.

The characteristics of an "in-between space" can help us explicate some of the challenges facing organizations and individuals as they engage in collaborative innovation. It appears that many organizations tend to underestimate the difficulties of engaging in collaborative innovation and the work that collaborating entails (C Huxham \& Vangen, 2005; S. Ollila \& Elmquist, 2011). Moving beyond uncertainty and ambiguity to achieve collaborative advantage (C. Huxham, 1996) is especially challenging when organizations who would ordinarily be considered as customers, suppliers, purchasers, contractors or competitors are now partners, brought into new relationships with one another: in such circumstances, when the outputs of the collaboration are uncertain, actors need to build trust (Fawcett et al, 2012) as well as new ways of doing things, to create and learn together.

Previous research does not offer much guidance regarding how the collaborating actors interact, what they do together and why. Doing innovation together can indeed be challenging as boundaries, motives and mandates of the individuals and/or actors often become blurred as collaborating entails dealing with multiple agendas and a continuous negotiation of relationships (Phillips, Lawrence, \& Hardy, 2000). Most forms of multi-actor collaboration can be expected to be a "tangled web of dynamic, ambiguous, and partially overlapping goal hierarchies" (Vangen \& Huxham, 2011p 752). Collaboration therefore requires that partners cope with different institutional or disciplinary logics, develop specific capabilities to collaborate in the unknown (M. Agogué et al., 2017) and deal with an unwillingness to compromise, political struggles and unrealistic expectations of one another. We know from empirical evidence that many collaborations collapse or do not create satisfactory value (Sivadas \& Dwyer, 2000), and to avoid this, developing a collaborative competence at the individual as well as the organizational level is considered essential, and consequently, focusing 
on the what and when of collaboration is not enough - there is also a need to consider how to collaborate.

Research shows that multi-actor collaboration involves complex and disorderly interactive processes and it is only by engaging in those processes that a collaborative competence can be nurtured, and successful outcomes repeatedly achieved (Susanne Ollila \& Yström, 2016). It has been proposed that successful collaboration requires initial identification and involvement of key actors; maintenance of the collaboration process; (long-term) implementation of collaborative outcomes (Arnaboldi \& Spiller, 2011) and a process that allows for continuous dialogue between collaborators (Fayard \& Metiu, 2014). This requires that collaboration is thought of as an on-going learning process, where social interactions form, develop and change within a collaborative space. Studying collaborative innovation through the lens of such an inbetween space, and especially focusing on what actors do together, how they interact and why, will offer new insights on how collaborative innovation can be fostered and sustained.

\section{Practices in collaborative innovation}

Focusing on how to do collaborative innovation in spaces in-between can be understood as an effort to elucidate the micro-foundations of collaborative innovation (Bogers et al., 2017). In this special section, our intention is to further explore and problematize one dimension of such micro-foundations - practices in collaborative innovation - in order to extend our knowledge about the constitution of collaboration in circumstances where the outcomes are uncertain or even unknown, and what happens as different actors (both individuals and organizations) engage in interaction to innovate together.

Why the focus on practices? In the innovation management literature, research has primarily focused on investigating technical, contractual or business aspects of organizations engaging in innovative activities outside organizational boundaries, without specific attention to the influence and roles of individuals in such interactions. As the organizational reality of innovative work has changed, in this special section we argue the need for a practice turn also in innovation management literature, building on the reasoning of Barley and Kunda (2001) and Corradi, Gherardi, and Verzelloni (2010). With a practice lens, we are encouraged to consider organizations as an ongoing routinized and recurrent accomplishment, something that is made and re-made using tools, language and our physical presence. Originally, the need for a practice turn in the field of organization studies grew out of a concern that theories where becoming disconnected from reality, from what was actually going on in organizations. In innovation management, a research field which holds both theoretical and practical relevance in high regard, practice-based approaches could be a fruitful way of developing empirically grounded theories and reconnect with the reality of innovation in modern organizational contexts.

Practice-based studies and practice theories reflect a broad field, but Nicolini (2012) propose that the general attraction of the practice idiom should be related to "its capacity to resonate with the contemporary experience that our world is increasingly in flux and interconnected, a 
world where social entities appear as the result of ongoing work and complex machinations, and in which boundaries around social entities are increasingly difficult to draw" (p 2). Practice-based approaches tend to emphasize a processual understanding of organizations as well as the world, recognizing organizations as both as the site and the outcome of work activity.

By specifically addressing practices in collaborative innovation, we aim to highlight the centrality of human actions and practices not only for organizational outcomes but also for collaborative outcomes. To investigate diverse forms of organizing for collaboration, characterized as complex, dynamic, distributed, mobile, transient, and unprecedented (Barley \& Kunda, 2001; Ciborra, 1996), a practice lens can be useful in understanding these kinds of novel, indeterminate and emergent phenomena that arise in spaces in-between. A practice perspective, with its focus on dynamics, relations, and enactment (Feldman \& Orlikowski, 2011), is thus particularly well-positioned to gain new insight into the microfoundations of collaborative innovation.

So, what exactly does studying "practices" imply? According to Gherardi (2009), there is a risk that "practice" could be assumed to be synonymous with "routine", "embodied skill", or just generally "what people do". Such assumptions often fail to recognize the object of study and its original and distinctive contribution to understanding the social order (ibid). Rather, practice theories can do more than just describe what people do. Practices are, in fact, meaning-making, identity-forming, and order-producing activities (Chia \& Holt, 2008; Nicolini, 2009). Similarly, Orlikowski (2002) proposed that "knowing" is not a static embedded capability or stable disposition of actors, but rather an ongoing social accomplishment, constituted and reconstituted as actors engage the world in practice. Thus, when we in this special section claim to be interested in exploring practices of collaborative innovation, this is not only a question of how collaborative innovation is done (activities), but also fundamental questions concerning the meaning of that which is done, and how such practices are constituting and shaping a collaborative space which we refer to as an "in-between space".

\section{Unpacking dynamics, relations and enactment - 3 contributions}

This special section features three articles dealing with topics as diverse as gamification, innovation spaces and networks of R \& D projects in the semiconductor industry. Each in their own way, these articles offer different avenues for reflection to advance a better understanding of collaborative innovation practices.

Naturally, there are many ways to study practices, and this special section does not aspire to present a "best practice" type of selection or even a representative one. Rather, our aspiration is that the three contributions included in this special section can ignite an inspiring discussion among researchers in the field of innovation management concerning the importance and relevance of a practice approach that captures and explicates some micro-level processes related to collaborative innovation. 
Based on the work of Feldman and Orlikowski (2011) on theorizing practice and practicing theory, this special section was inspired to invite contributions that would enable us to unpack the dynamics, relations and enactment of collaborative innovation practices. The three papers included in this section all touch upon these dimensions, although in different ways and to different degrees. The papers draw on extensive and rich empirical material, offering deep and detailed insights into different aspects of collaborative practices. The empirical contexts in which collaborative innovation practices were studied also differs across the papers, illustrating the multitude of organizational settings where collaborative practices are used today.

Unpacking dynamics implies an aspiration to understand how people act in organizational contexts, and to explore the everyday activity of organizing in both its routine and improvised forms (Feldman \& Orlikowski, 2011) - what are they doing as they engage in collaborative innovation and how are they doing it? This typically infers a dynamic that can be recognized, analyzed and problematized. In the first paper of this special section on the use of gamification to support co-creation processes, Patricio and colleagues suggest that a structured and coordinated approach is necessary to provide a clear framework that facilitates open discussion, team alignment and the achievement of concrete results, and that overcomes potential lack of mutual understanding. This proposition of structuration of the collaboration echoes the findings of the second paper of this special section by Faccin and colleagues that focuses on how a hub firm orchestrates an R\&D network through collaborative practices. The authors indeed suggest that structuring collaboration - framed as orchestration - is key, especially to ensure sharing, acquiring and deploying knowledge among the different stakeholders of the collaboration. However, complementary to known orchestration practices, according to the authors, this also entails a specific type of orchestration process that has significant impact on collaboration dynamics, namely network reconfiguration, which involves the ability to continuously disassociate stakeholders from the collaboration and attract new one. Complementing this approach is the third paper of this special section, where Caccamo and colleagues address how innovation spaces foster effective collaborative innovation. They offer insights into how tangible artifacts constantly displayed in innovation studios may support collaborative innovation as the work of others can offer inspiration, act as generative poles of ideas and challenge existing assumptions, while creating a shared knowledge capital that is freely available to use.

Second, unpacking relations can be understood as an aspiration to grasp relations between the actions people take and the structures of organizational life (Feldman \& Orlikowski, 2011) who is doing something and in relation to what or whom in the collaboration? Relations can be seen as both an empirical phenomenon inherent in the very idea of collaboration, but also a theoretical phenomenon seeking to explain patterns and interconnections in the dynamics of the collaboration. In their study, Patricio and colleagues show that within a collaboration, effective and generative inter-stakeholder interactions are carefully handled. By studying the impact of a gamification methodology to foster collaborative innovation, the authors argue that in such context, a facilitator has a key role to play to create a genuine dialogue among the different stakeholders. In that vein, the authors suggest that the experience and abilities of the facilitator are a determinant factor in achieving concrete results and participants' engagement, and that 
facilitation should be extended over a longer period of time, beyond the sole gamification activities. Such facilitation activities may trigger trust and legitimacy of the collaborative processes, which is supported by Faccin and colleagues, who argue that these factors are essential to sustain knowledge mobility and novel idea appropriability among the members of the collaboration. Concrete symbols may also be used to foster a trusting climate and form bridges that can open up for new kinds of interaction and relations to form. Caccamo and colleagues suggest that for instance glass entry doors and open spaces convey a completely different feeling compared to the aura of secrecy that normally surrounds R\&D projects, reflecting a spirit of openness was hoped to characterize relationships in the collaboration. And beyond the mere materiality of innovation spaces, the authors of the paper propose that tangible artefacts mobilized during collaborative innovation may act as boundary objects. Relational engagement is stimulated by the affordances of the boundary objects, and facilitators, such as instructors in business studios, foster collective actualization by utilizing boundary objects during collaborative innovation work.

Going one step further, unpacking enactment can be understood as an aspiration to understand practices as the primary building blocks of social reality (Feldman \& Orlikowski, 2011) - why are people acting in specific ways and what is the meaning and implication of such actions for the collaboration? How and why is the collaboration in itself shaping what actions become possible? Enactment becomes a philosophical phenomenon attempting to explicate the constitutive role of practices in producing organizational reality. In that line of idea, Patricio and colleagues elicit how gamification may help to build a collaborating environment where everyone feels free to express their inner thoughts, even if it meant sometimes going against what others are suggesting. In doing so, it opens up new possibilities in crafting new ideas, making intangible thoughts more tangible and disclosing clearer insights, which can be understood as the foundation from which the collaboration can be sustained and continuously developed. This resonates with the reflexive attitude that Caccamo and colleagues advocate as a means to mindfully live the collaboration. The continuous regeneration of the collaboration is also visible in the paper by Faccin and colleagues, who through the introduction of a concept like network reconfiguration as a crucial aspect of network orchestration points to the continuous work needed to enact and uphold the collaboration. Such practices of reconfiguration, regeneration and continuous adaptation speak to the resilience, robustness and ultimately success of the collaboration, but are often less recognized or underestimated.

\section{New areas of inquiry - what is the agenda moving forward?}

These three teams of researchers have offered novel and interesting insights on collaborative innovation practices. Undoubtedly, research on this topic shows bright promises! It is therefore with great anticipation that we look forward to read and hear of future work inspired by the included three articles.

Specifically, we advocate that innovation management scholars should pay further attention to practices, and encourage practice scholars to set their sights on the burgeoning collaborative innovation context, as we see rich opportunities for relevant contributions in the intersection 
between these fields. A better understanding of collaborative innovation practices will facilitate a more informed and relevant discussion concerning management and governance of collaborative innovation, at the individual level as well as the organizational or collaborative level. Such discussion may benefit from a number of important questions examined in future research. Among many pertinent examples, one may ask: How do power relations influence collaborative practices, and as collaborative practices develop and are adopted, how does that influence the partners? How can different organizational forms or designs of spaces in-between influence the development and/or enactment of collaborative practices? How do organizations experiment with collaborative innovation in in-between spaces and learn from such experimentation? What are the cognitive dynamics of actors engaging in collaborative innovation? What role does the "context of unknown" or the "search for breakthrough/disruption" play in the development of spaces in-between?

To facilitate such advances, it seems appropriate to encourage researchers to use a wide range of methodological approaches to study practices in collaboration for innovation in and between contemporary organizations. Or, in other words, to better understand how such practices shapes and are shaped by the spaces in-between that renders such spaces conducive to the emergence of new ideas and knowledge and allows us to capture the value created jointly. More specifically, recent initiatives to discuss research methodology in the field of innovation management, e.g. in a forthcoming special issue in R\&D management (Ritala, Schneider, \& Michailova, 2018), highlights the need for further reflection on what research methodologies are used in the field and what such methodologies imply for what can be said on a general level about the current state of organizing and managing innovation. With a particular interest in understanding practices in innovation management, the papers included in this special section allow us to suggest that studying practices in innovation management require rigorous study designs that allow extensive data collection (often qualitative data but quantitative could also be relevant) on a highly detailed level and typically over an extended period of time. However, longitudinal, ethnographic or even participatory study designs are still rather unusual in innovation management, and such studies have traditionally not easily been published in the journal article format. We argue that there is a great potential for practice studies in this particular field, but this also require innovation management scholars to consider alternative ways when designing and positioning their studies in order to further the knowledge development related to collaborative innovation practices. With this in mind, and as a concluding note, we hope that the publication of this special section will inspire the emergence of a community of researchers interested in discussing their projects, difficulties and ambitions related to the study of collaborative innovation practices.

\section{Anna Yström}

\section{Marine Agogué}




\section{References}

Agogué, M., Berthet, E., Fredberg, T., Le Masson, P., Segrestin, B., Stoetzel, M., .. . Yström, A. (2017). Explicating the role of innovation intermediaries in the "unknown": a contingency approach. Journal of Strategy and Management, 10(1), 19-39.

Agogué, M., Yström, A., \& Le Masson, P. (2013). Rethinking the role of intermediaries as an architect of collective exploration and creation of knowledge in open innovation. International Journal of Innovation Management, 17(2), 1350007-.

Arnaboldi, M., \& Spiller, N. (2011). Actor-network theory and stakeholder collaboration: The case of Cultural Districts. Tourism management, 32(3), 641-654.

Baldwin, C., \& von Hippel, E. (2011). Modeling a Paradgim Shift: From Producer Innovation to User and Open Collaborative Innovation. Organization Science, 22(6), 1399-1417.

Barley, S. R., \& Kunda, G. (2001). Bringing Work Back In. Organization Science, 12(1), 7695.

Bhabha, H. K. (1994). The location of culture: Psychology Press.

Bogers, M., Zobel, A.-K., Afuah, A., Almirall, E., Brunswicker, S., Dahlander, L., . . . Haefliger, S. (2017). The open innovation research landscape: Established perspectives and emerging themes across different levels of analysis. Industry and Innovation, 24(1), 8-40.

Chia, R., \& Holt, R. (2008). On managerial knowledge. Management Learning, 39(2), 141158.

Ciborra, C. U. (1996). The platform organization: Recombining strategies, structures, and surprises. Organization Science, 7(2), 103-118.

Corradi, G., Gherardi, S., \& Verzelloni, L. (2010). Through the practice lens: Where is the bandwagon of practice-based studies heading? Management Learning, 41(3), 265-283.

Dougherty, D. (2017). Organizing for innovation in complex innovation systems. Innovation. doi:DOI: $10.1080 / 14479338.2016 .1245109$

Fayard, A.-L., \& Metiu, A. (2014). The role of writing in distributed collaboration. Organization Science, 25(5), 1391-1413.

Feldman, M. S., \& Orlikowski, W. J. (2011). Theorizing practice and practicing theory. Organization Science, 22(5), 1240-1253.

Furnari, S. (2014). Interstitial spaces: Microinteraction settings and the genesis of new practices between institutional fields. Academy of Management review, 39(4), 439-462.

Huizingh, E. (2011). Open innovation: State of the art and future perspectives. Technovation, 31(1), 2-9. doi:10.1016/j.technovation.2010.10.002

Huxham, C. (1996). Creating collaborative advantage. London: Sage.

Huxham, C., \& Vangen, S. (2005). Managing to Collaborate: The theory and practice of collaborative advantage. Oxon, U.K.: Routledge.

Kellogg, K. C. (2009). Operating room: Relational spaces and microinstitutional change in surgery. American Journal of Sociology, 115(3), 657-711.

Kellogg, K. C., Orlikowski, W. J., \& Yates, J. (2006). Life in the trading zone: Structuring coordination across boundaries in postbureaucratic organizations. Organization Science, 17(1), 22-44.

Nicolini, D. (2009). Zooming in and out: Studying practices by switching theoretical lenses and trailing connections. Organization Studies, 30(12), 1391-1418.

Nicolini, D. (2012). Practice theory, work, and organization: An introduction: OUP Oxford.

Ollila, S., \& Elmquist, M. (2011). Managing Open Innovation: Exploring Challenges at the Interfaces of an Open Innovation Arena. Creativity and Innovation Management, 20(4), 273-283. doi:10.1111/j.1467-8691.2011.00616.x 
Citation: Yström, A., \& Agogué, M. (2020). Exploring practices in collaborative innovation: Unpacking dynamics, relations, and enactment in in-between spaces. Creativity and Innovation Management, 29(1), 141-145.

Ollila, S., \& Yström, A. (2016). Exploring Design Principles of Organizing for Collaborative Innovation: The Case of an Open Innovation Initiative. Creativity and Innovation Management, 25(3), 363-377. doi:10.1111/caim.12177

Ollila, S., \& Yström, A. (in press). Open Laboratories as "In-between Spaces". In A. Fritzsche, J. M. Jonas, A. Roth, \& K. M. Möslein (Eds.), Innovating in the Open Lab: The new potential for interactive value creation across organizational boundaries. Oldenbourg: De Gruyter.

Orlikowski, W. J. (2002). Knowing in practice: Enacting a collective capability in distributed organizing. Organization Science, 13(3), 249-273.

Phillips, N., Lawrence, T. B., \& Hardy, C. (2000). Inter-organizational collaboration and the dynamics of institutional fields. Journal of Management Studies, 37(1).

Ritala, P., Schneider, S., \& Michailova, S. (2018). Call for papers: Special issue on Innovation Management Research Methods. R\&D Management.

Sivadas, E., \& Dwyer, F. R. (2000). An examination of organizational factors influencing new product success in internal and alliance-based processes. Journal of Marketing, 64, 3149.

Vangen, S., \& Huxham, C. (2011). The tangled web: Unraveling the principle of common goals in collaborations. Journal of Public Administration Research and Theory, 22(4), 731760 . 